\title{
The impact of pulmonary metastasectomy from gastric cancer
}

\author{
YOHEI OGURI, MASAYUKI OKUI, TAKASHI YAMAMICHI, AYAKA ASAKAWA, \\ MASAHIKO HARADA and HIROTOSHI HORIO
}

\begin{abstract}
Department of Thoracic Surgery, Tokyo Metropolitan Cancer and Infectious Diseases Center Komagome Hospital, Tokyo 113-8677, Japan
\end{abstract}

Received August 14,2018; Accepted April 22, 2019

DOI: $10.3892 / \mathrm{mco} .2019 .1910$

\begin{abstract}
Gastric cancer remains the most commonlyoccurring cancer and the third most frequent cause of cancer-associated mortality in Japan. Solitary pulmonary metastasis of gastric cancer is rare and the outcome of pulmonary metastasectomy is still unclear. Herein we report the impact of pulmonary resection in patients with metastasis from gastric cancer. The present study retrospectively reviewed the preoperative data and clinical courses of 10 patients who underwent pulmonary resection for metastasis from gastric cancer at our institution between July 1986 and December 2017. The data on the outcomes, including morbidity, mortality and survival, were obtained from the patient records. All patients were followed-up from the time of pulmonary resection until mortality or referral to another hospital. The statistical analyses were performed using EZR (Saitama Medical Center, Jichi Medical University, Saitama, Japan), which is a graphical user interface for the R software program (The R Foundation for Statistical Computing, Vienna, Austria). The study population included 7 male patients and 3 female patients. A total of 5 patients underwent total gastrectomy, and 5 underwent distal gastrectomy. The median disease-free interval after initial gastric resection was 34.5 months. Five patients received adjuvant chemotherapy, of the 10 thoracotomies, 5 were lobectomy, 3 were wedge resection and 2 were segmentectomy. The median overall survival following pulmonary metastasectomy was 59 months and the 5 -year survival rate was $40.5 \%$. Taken together, the results of the present study suggest that pulmonary
\end{abstract}

Correspondence to: Dr Yohei Oguri, Department of Thoracic Surgery, Tokyo Metropolitan Cancer and Infectious Diseases Center Komagome Hospital, 3-18-22 Honkomagome, Bunkyo-ku, Tokyo 113-8677, Japan

E-mail: oguriyohei@cick.jp

Abbreviations: CT, computed tomography; PET/CT, positron emission tomography/computed tomography; JCGC, the Japanese Classification of Gastric Carcinoma; OS, overall survival; DFS, disease-free survival

Key words: gastric cancer, pulmonary metastasis, pulmonary resection, metastasectomy, solitary metastasis resection may be an effective therapeutic option for metastatic gastric cancer when a patient has a solitary metastatic lesion.

\section{Introduction}

Gastric cancer remains the most common cancer and the third most frequent cause of cancer death in Japan, although its incidence and mortality have declined over the years. Early discovery and subsequent treatment are important for survival in the case of cancer. Resection of pulmonary metastases for selected patients with malignancies, such as colorectal cancer and renal cancer, has been demonstrated as effective $(1,2)$. However, gastric cancer mainly recurs by spreading intra-abdominally or as liver metastasis, and solitary pulmonary metastasis of gastric cancer is rare. As such, the outcome of metastasectomy is unknown. We therefore aimed to confirm the effectiveness of pulmonary metastasectomy for gastric cancer.

Gastric cancer remains the most common cancer and the third most frequent cause of cancer death in Japan, although its incidence and mortality have declined over the years. Demographic trends differ by tumor location and histology. While there has been a marked decline in distal, intestinal type gastric cancers, the incidence of proximal, diffuse type adenocarcinomas of the gastric cardia has been increasing, particularly in Japan. Prognosis of unresectable, metastatic gastric cancer is still low and five-year survival rate for unresectable, metastatic gastric cancer is about $5-20 \%$, with median overall survival being less than 1 year (1). Early discovery and subsequent treatment are important for survival in the case of gastric cancer.

Pulmonary metastasis usually occurs at advanced stages of malignancies, however resection of pulmonary metastases for selected patients with malignancies, such as colorectal cancer and renal cancer, has been demonstrated as effective $(2,3)$. However, gastric cancer mainly recurs by spreading intra-abdominally or as liver metastasis, and pulmonary metastasis of gastric cancer is very rare. Koga et al (4) reported 7 $(0.5 \%)$ pulmonary metastases in 1,314 gastric cancer patients and Kong et al (5), reported 193 (0.96\%) pulmonary metastasis in 20,187 gastric cancer patients. Moreover, approximately $80 \%$ of patients with lung metastasis had concomitant metastasis to other organs such as peritoneum, liver and bone (5). As such, the outcome of resection of pulmonary metastasis have not been extensively studied. We therefore aimed to confirm the effectiveness of pulmonary metastasectomy for gastric cancer. 
Table I. Clinicopathological features of patients with primary gastric cancer.

\begin{tabular}{|c|c|c|c|c|c|c|c|c|c|c|c|}
\hline No. & Sex & $\begin{array}{c}\text { Age } \\
\text { (years) }\end{array}$ & $\begin{array}{l}\text { Types of } \\
\text { gastrectomy }\end{array}$ & $\begin{array}{c}\text { Macroscopic } \\
\text { type }\end{array}$ & $\begin{array}{l}\text { Histological } \\
\text { type }\end{array}$ & pT & $\mathrm{pN}$ & ly & $\mathrm{v}$ & $\begin{array}{l}\text { Chemotherapy } \\
\text { after } \\
\text { gastrectomy }\end{array}$ & $\begin{array}{c}\text { Disease-free } \\
\text { interval } \\
\text { (months) }\end{array}$ \\
\hline 1 & Male & 82 & Total & 2 & Tub1 & SS (T3) & 0 & 1 & 2 & - & 19 \\
\hline 2 & Female & 76 & Total & 2 & Tub1 & SS (T3) & 1 & 1 & 1 & - & 0 \\
\hline 3 & Female & 63 & Total & 2 & Pap & SI (T4b) & 1 & 3 & 1 & 5-FU+CDDP & 49 \\
\hline 4 & Male & 70 & Distal & 2 & Pap & $\mathrm{MP}(\mathrm{T} 2)$ & 0 & 0 & 3 & - & 59 \\
\hline 5 & Male & 53 & Distal & 3 & Tub1 & SS (T3) & 1 & 3 & 0 & 5-FU+1-LV & 48 \\
\hline 6 & Female & 55 & Total & 2 & Tub2 & SS (T3) & 1 & 2 & 0 & $+($ unspecified $)$ & 24 \\
\hline 7 & Male & 71 & Total & 0-IIc & Tub2 & $\mathrm{SM}(\mathrm{T} 1 \mathrm{~b})$ & 0 & 1 & 0 & - & 45 \\
\hline 8 & Male & 81 & Distal & 2 & Pap & SS (T3) & 2 & 1 & 1 & - & 7 \\
\hline 9 & Male & 72 & Distal & 2 & Tub2 & SE (T4a) & 3 & 1 & 3 & S-1 & 14 \\
\hline 10 & Male & 63 & Distal & 3 & Tub2 & SI (T4b) & 3 & 1 & 2 & S-1 & 51 \\
\hline
\end{tabular}

SM, submucosa; MP, muscularis propria; SS, subserosa; SE, exposed beyond the serosa; SI invade adjacent structure.

\section{Patients and methods}

We retrospectively reviewed the preoperative data and clinical courses of patients who underwent pulmonary resection for metastasis from gastric cancer at our institution between July 1986 and December 2017. Ten patients underwent pulmonary resection and a total of 1,714 patients underwent gastrectomy for gastric cancer during the period. The study protocol was examined and approved by the Ethics Committee of Tokyo Metropolitan Cancer and Infectious Diseases Center Komagome Hospital. The pulmonary lesions were detected on chest computed tomography (CT) or plain chest X-ray. In general, we used Thomford's criteria for resection of pulmonary metastases (6). Positron emission tomography/computed tomography (PET/CT) was used to detect extrapulmonary metastases, thereby preventing needless surgery. We reviewed the medical records and collected the following data: Operative record, pathological data, induction and/or adjuvant therapy record, and concomitant sites other than the lung. The TNM classification for stomach tumors was based on the 3rd edition of the Japanese Classification of Gastric Carcinoma (JCGC) (7).

The median follow-up period of the patients after the pulmonary metastasectomy was 59 months (range, 3-156 months). Overall survival (OS) was defined as the interval between the date of pulmonary resection of lung metastases and the date of death from any cause or the date of the last follow-up visit. The disease-free survival (DFS) time was defined as the interval between the date of gastric surgery and the date of recurrence. OS was estimated using the Kaplan-Meier product method. The statistical analyses were performed with EZR (Saitama Medical Center, Jichi Medical University, Saitama, Japan), which is a graphical user interface for R (The R Foundation for Statistical Computing, Vienna, Austria) (8).

\section{Results}

Clinicopathological characteristics in primary gastric cancer. The clinicopathological features of patients with primary gastric cancer are summarized in Table I. There were 7 males and
3 females, and the mean age was 70.5 years (range, 53-82 years). Macroscopic features of gastric cancer were type 2 for 7 patients, type 3 for 2 patients and 0 -IIc for 1 patient. Macroscopic features of type 2 tumors represent ulcerated tumors with raised margins surrounded by a thickened gastric wall with clear margins and type 3 tumors represent ulcerated tumors without clear margins. Type 0 -IIa tumors represent slightly elevated tumors (7). Among these patients, $40 \%$ had N1 disease, $30 \%$ had N0, 20\% had N3 and 10\% had N2. Five patients underwent total gastrectomy and the others underwent distal gastrectomy. Lymphatic permeation was observed in 9 and vascular invasion in 7. Five patients received adjuvant chemotherapy ( $\mathrm{S}-1$ for 2 , 5-fluorouracil/cisplatin for 1 and 5-fluorouracil/leucovorin for 1; the other was not described specifically). The patient \#2 had a synchronous lung metastasis of gastric cancer and the median DFS was 34.5 months (range, 0-59 months).

Surgical outcomes for pulmonary metastases of gastric cancer. Surgical outcomes for pulmonary metastases from gastric cancer are summarized in Table II. All patients had solitary pulmonary lesions and the median tumor size was $1.9 \mathrm{~cm}$ (range, $0.8-5.2 \mathrm{~cm}$ ). Of the 10 thoracotomies, 5 were lobectomy, 3 were wedge resection and 2 were segmentectomy. Tumor recurrence occurred in several organs in 3 patients after pulmonary metastasectomy. One patient had lung recurrence, 1 had liver metastasis and 1 had left ilium metastasis.

Prognosis of pulmonary metastasectomy of gastric cancer. The OS after pulmonary metastasectomy is shown in Fig. 1. The median OS of the 10 patients was 59 months and the 5 -year survival rate was $40.5 \%$. The median OS was 42 months in patients with chemotherapy after pulmonary resection and 56 months in those without chemotherapy.

\section{Discussion}

Pulmonary metastasectomy has become a therapeutic option for metastases of gastrointestinal tumors. In colon and rectal cancers, indications for pulmonary metastasectomy include: 
Table II. Surgical outcomes of patients with pulmonary metastases from gastric cancer.

\begin{tabular}{|c|c|c|c|c|c|c|}
\hline No. & $\begin{array}{c}\text { Diagnosis before } \\
\text { pulmonary resection }\end{array}$ & $\begin{array}{c}\text { Size of } \\
\text { resected } \\
\text { nodule }(\mathrm{cm})\end{array}$ & $\begin{array}{l}\text { Mode of } \\
\text { pulmonary } \\
\text { resection }\end{array}$ & $\begin{array}{c}\text { Chemotherapy } \\
\text { after } \\
\text { resection }\end{array}$ & $\begin{array}{l}\text { Prognosis after } \\
\text { pulmonary } \\
\text { resection }\end{array}$ & Cause of death \\
\hline 1 & Primary lung cancer & 5.2 & Lobectomy & - & Died at 3 months & Pneumonia \\
\hline 2 & Primary lung cancer & 3.2 & Lobectomy & - & Died at 59 months & Unknown \\
\hline 3 & Metastasis of gastric cancer & 1.6 & Segmentectomy & - & Alive at 76 months & \\
\hline 4 & Metastasis of gastric cancer & 2.5 & Segmentectomy & - & Alive at 156 months & \\
\hline 5 & Primary lung cancer & 1.8 & Partial resection & S-1 & Alive at 143 months & \\
\hline 6 & Primary lung cancer & 2.4 & Lobectomy & S-1 & Alive at 5 months & \\
\hline 7 & Primary lung cancer & 1.8 & Lobectomy & - & Died at 56 months & Pneumonia \\
\hline 8 & Primary lung cancer & 2 & Partial resection & - & Died at 7 months & Pulmonary metastasis \\
\hline 9 & Primary lung cancer & 0.8 & Lobectomy & - & Died at 8 months & Liver metastasis \\
\hline 10 & Primary lung cancer & 1.2 & Partial resection & S-1 & Alive at 42 months & \\
\hline
\end{tabular}

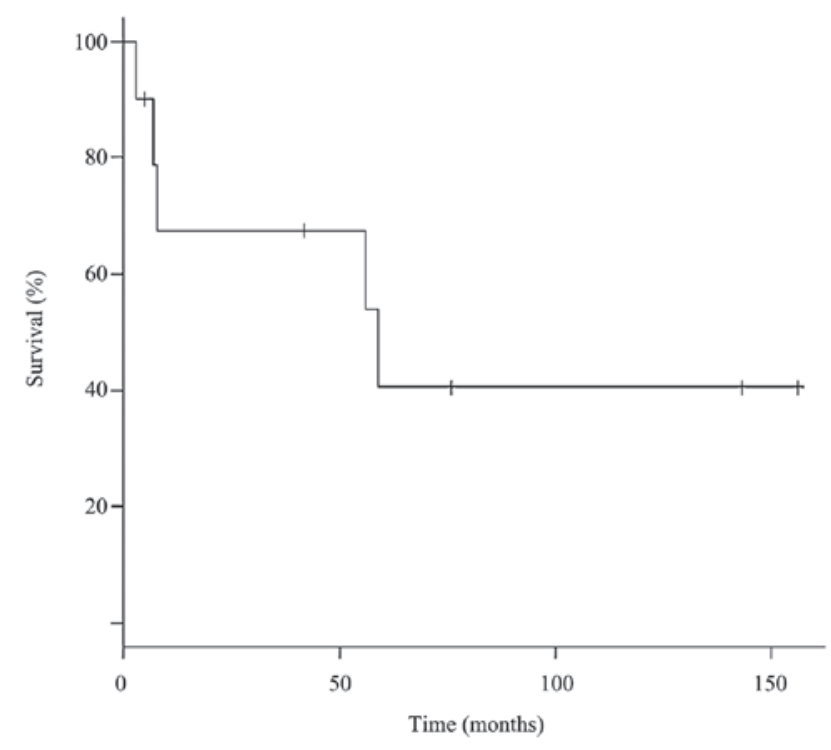

Figure 1. Overall survival after pulmonary metastasectomy from gastric cancer.

i) feasible R0 resection; ii) the patient can tolerate pulmonary resection; iii) control of the primary tumor is warranted; and iv) absence of extrathoracic lesions (9). However pulmonary metastasis of gastric cancer is often unresectable because of metastatic forms such as lymphagitic carcinomatosis and carcinomatous pleuritis (10). The incidence of pulmonary metastases from gastric cancer ranges from 19.4 to $52.4 \%$ based on autopsy cases $(11,12)$. On the other hand, resectable solitary pulmonary metastases have only been identified in $0.1 \%$ of patients who have undergone curative resection of gastric cancer (13).

Thus far, it has been reported that lymphatic permeation is more important than vascular invasion in pulmonary metastases from gastric cancer (13). In our patients, the most common histopathological feature of gastric wall invasion was that the tumor invaded deeper than the serosa with lymphatic permeation.

Although the median survival after diagnosis of pulmonary metastasis is 4 months, and even in patients treated by chemotherapy alone, the reported 5-year survival rate is only $2-4 \%(5,14,15)$, pulmonary resection for selected patients with solitary metastasis was reported to provide a relatively favorable outcome $(16,17)$. The median OS differed between the groups with and without chemotherapy. Chemotherapy following surgery may be able to prolong the OS; however, our study included only a small number of patients and one patient who received chemotherapy after pulmonary resection (patient no. 6) was referred back to their family doctor. Thus, it is unclear whether chemotherapy after resection can improve the prognosis.

Solitary pulmonary metastases from gastric cancer after complete resection are difficult to diagnose before pulmonary resection. Kobayashi et al (18), reported that a short tumor doubling time and a low tumor disappearance rate are useful for preoperatively distinguishing metastatic gastric cancer from primary adenocarcinoma of the lung. Regardless of radiological findings, solitary pulmonary lesions detected after curative resection of gastric cancer are occasionally difficult to diagnose. Surgical resection is the most reliable way to differentiate metastases from primary lung cancer. These two entities differ greatly in their prognosis and an exact histological diagnosis is essential.

Some limitations exist in this study. First, the study was retrospective small cases and we should collect more datas. Second, we selected patients who had only solitary lung metastasis, causing a selection bias. If patients have multiple metastases, it becomes difficult to choose surgical treatment instead of systematic therapy. Third, some patients did not receive adjuvant chemotherapy even though they had advanced cancer. If they had all received the same regimen, the DFS, mode of pulmonary resection and prognosis may have improved.

We conclude that pulmonary resection for metastasis of gastric cancer may be an effective therapeutic option when there is a solitary metastatic lesion.

\section{Acknowledgements}

Not applicable. 


\section{Funding}

No funding was received.

\section{Availability of data and materials}

The datasets obtained and/or analyzed during the present study are available from the corresponding author on reasonable request.

\section{Authors' contributions}

YO, MO and HH analyzed patient data and wrote the manuscript. TY, AA and MH collected the data and critically revised the manuscript.

\section{Ethics approval and consent to participate}

This original article was approved by the institutional review board, and written informed consent was obtained from all the patients.

\section{Patient consent for publication}

Written consent for publication was obtained from all the patients.

\section{Competing interests}

The authors declare that they have no competing interests.

\section{References}

1. Kamangar F, Dores GM and Anderson WF: Patterns of cancer incidence, mortality, and prevalence across five continents Defining priorities to reduce cancer disparities in different geographic regions of the world. J Clin Oncol 24: 2137-2150, 2006.

2. Lin BR, Chang TC, Lee YC, Lee PH, Chang KJ and Liang JT: Pulmonary resection for colorectal cancer metastases: Duration between cancer onset and lung metastasis as an important prognostic factor. Ann Surg Oncol 16: 1026-1032, 2009.

3. Bölükbas S, Kudelin N, Eberlein M, Fisseler-Eckhoff A and Schirren J: The influence of the primary tumor on the long-term results of pulmonary metastasectomy for metastatic renal cell carcinoma. Thorac Cardiovasc Surg 60: 390-397, 2012.

4. Koga S, Takebayashi M, Kaibara N, Nishidoi H, Kimura O, Kawasumi $\mathrm{H}$ and Makino $\mathrm{M}$ : Pathological characteristics of gastric cancer that develop hematogenous recurrence, with special reference to the site of recurrence. J Surg Oncol 36: 239-242, 1987
5. Kong JH, Lee J, Yi CA, Park SH, Park JO, Park YS, Lim HY, Park KW and Kang WK: Lung metastases in metastatic gastric cancer: Pattern of lung metastases and clinical outcome. Gastric Cancer 15: 292-298, 2012.

6. Thomford NR, Woolner LB and Clagett OT: The surgical treatment of metastatic tumor in the lung. J Thoracic Cardiovasc Surg 49: 357-363, 1965.

7. Sano T and Aiko T: New Japanese classifications and treatment guidelines for gastric cancer: Revision concepts and major revised points. Gastric Cancer 14: 97-100, 2011.

8. Kanda Y: Investigation of the freely-available easy-to-use software EZR for medical statistics. Bone Marrow Transplant 48: 452-458, 2013

9. NCCN clinical practice guidelines in Oncology, Colon Cancer. http:/www.nccn.org/professionals/physician_gls/pdf/colon.pdf Accessed 13 March, 2017.

10. Nakayama H1, Ichinose S, Kato Y, Ito H, Masui K and Kameda Y: Long-term survival after a surgical resection of pulmonary metastases from gastric cancer: report of a case. Surg Today 38: $150-153,2008$.

11. Dupont JB Jr, Lee JR, Burton GR and Cohn I Jr: Adenocarcinoma of the stomach: Review of 1,497 cases. Cancer 41: 941-947, 1978.

12. Ishii T, Ikegami N, Hosoda $\mathrm{Y}$, Koide $\mathrm{O}$ and Kaneko M: The biological behavior of gastric cancer. J Pathol 134: 97-115, 1981.

13. Kanemitsu Y, Kondo H, Katai H, Nakayama H, Asamura H, Tsuchiya R and Naruke T: Surgical resection of pulmonary metastases from gastric cancer. J Surg Oncol 69: 147-150, 1998.

14. Ohkuwa M, Ohtsu A, Boku N, Yoshida S, Miyata Y, Shirao K, Shimada Y and Kurihara M: Long-term results for patients with unresectable gastric cancer who received chemotherapy in the Japan Clinical Oncology Group (JCOG) trials. Gastric Cancer 3: $145-150,2000$.

15. Yoshida M, Ohtsu A, Boku N, Miyata Y, Shirao K, Shimada Y, Hyodo I, Koizumi W, Kurihara M, Yoshida S and Yamamoto S: Long-term survival and prognostic factors in patients with metastatic gastric cancers treated with chemotherapy in the Japan Clinical Oncology Group (JCOG) study. Jpn J Clin Oncol 34: 654-659, 2004.

16. Nakayama H, Ichinose $S$, Kato $Y$, Ito H, Masui $K$ and Kameda $Y$ : Long-term survival after a surgical resection of pulmonary metastases from gastric cancer: Report of a case. Surg Today 38: $150-153,2008$

17. Ogura M, Tanaka N, Furuya T, Nomura Y, Nagai M, Takahashi M, Takayama T, Hirao H, Nakamura $H$ and Suzuki $Y$ : A case of long-term survival after undergoing $\mathrm{S}-1$ treatment and splenectomy for liver, lung and splenic metastases following curative distal gastrectomy for gastric cancer. Gan To Kagaku Ryoho 37: 1125-1129, 2010 (In Japanese).

18. Kobayashi Y, Fukui T, Ito S, Shitara K, Ito S, Hatooka S and Mitsudomi T: Pulmonary metastasectomy for gastric cancer: A 13-year single-institution experience. Surg Today 43: 1382-1389, 2013. 